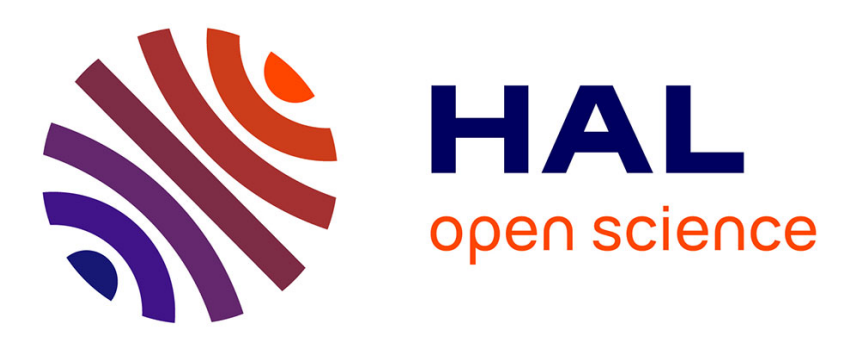

\title{
Ethanol-water co-condensation into hydrophobic mesoporous thin films: example of a photonic ethanol vapor sensor in humid environment
}

\author{
Mickael Boudot, Andrea Cattoni, David Grosso, Marco Faustini
}

\section{To cite this version:}

Mickael Boudot, Andrea Cattoni, David Grosso, Marco Faustini. Ethanol-water co-condensation into hydrophobic mesoporous thin films: example of a photonic ethanol vapor sensor in humid environment. Journal of Sol-Gel Science and Technology, 2017, 81, pp.95-104. 10.1007/s10971-016-4084-2 . hal01332598

\section{HAL Id: hal-01332598 \\ https://hal.sorbonne-universite.fr/hal-01332598}

Submitted on 16 Jun 2016

HAL is a multi-disciplinary open access archive for the deposit and dissemination of scientific research documents, whether they are published or not. The documents may come from teaching and research institutions in France or abroad, or from public or private research centers.
L'archive ouverte pluridisciplinaire HAL, est destinée au dépôt et à la diffusion de documents scientifiques de niveau recherche, publiés ou non, émanant des établissements d'enseignement et de recherche français ou étrangers, des laboratoires publics ou privés. 


\title{
Ethanol-water co-condensation into hydrophobic mesoporous thin films: Example of a photonic ethanol vapor sensor in humid environment
}

\author{
Mickael Boudot ${ }^{1,3}$, Andrea Cattoni, ${ }^{2}$ David Grosso, ${ }^{3}$ Marco Faustini ${ }^{3}$ \\ ${ }^{1}$ Institute for Materials Chemistry and Engineering, Kyushu University, 6-1 Kasuga-Koen, \\ Kasuga, Fukuoka 816-8580, Japan. \\ ${ }^{2}$ Laboratoire de Photonique et de Nanostructure, CNRS, Université Paris-Saclay, route de \\ Nozay, F-91460 Marcoussis, France \\ ${ }^{3}$ Sorbonne Universités, UPMC Univ Paris 06, CNRS, Collège de France, UMR 7574, Chimie de la \\ Matière Condensée de Paris, F-75005, Paris.
}

\begin{abstract}
In this work, we report a new generation of sol gel photonic vapor sensor based on water repellent methyl functionalized mesoporous silica thin films for the detection of alcohol vapors. Relative humidity, generally accountable for sensor performance deterioration, was demonstrated as a key parameter to detect and enhance sensor sensitivity concerning ethanol. The ethanol-assisted water vapors capillary condensation into hydrophobic mesopores was observed and investigated as an innovative sensing mechanism. We showed that water condensation was triggered by the surfactant-like behavior of alcohol molecules whose alkyl moieties preferentially interact with the hydrophobic walls and reversibly switch the surface energy from hydrophobic to hydrophilic. Influence of the ethanol and water pressure conditions for which the capillary condensation occurs were studied by in situellipsometry. This study revealed a synergic mechanism of co-adsorption where the minimum ethanol concentration allowing water capillary adsorption decreases when humidity increases. Nanopatterned diffraction gratings films, fabricated via a nanoimprinting process, were demonstrated to be efficient transductor to transform the capillary induced nanoscale variations of refractive index of the porous materials into optical signals easily measurable by conventional camera. Sensing results exhibited an ethanol vapor pressure threshold limit of detection of $\mathrm{P} / \mathrm{P}_{0}{ }^{\mathrm{EtOH}}=0.07$ at $100 \%$ relative humidity and typical response and regeneration times are below one minute.
\end{abstract}

Keywords : Hydro-alcoholic capillary co-condensation, sol gel nanoimprinting, optical sensor, ethanol sensing.

\section{Introduction}

Protection of our environment at global and locale scale has become one of the major issues in past years and continues to be a subject of concern today and for the future, especially regarding the atmospheric pollution. Indeed, the increase of concentrations of greenhouse effect gases in atmosphere such as $\mathrm{CO}_{2}$ or methane (etc...) is now proved to be a cause of global warming. Air pollution has also a more direct impact in human life, as examples toxic gases like $\mathrm{NO}_{x}, \mathrm{CO}, \mathrm{CO}_{2}, \mathrm{H}_{2} \mathrm{~S}$ and $\mathrm{VOC}^{\prime}$ 's (ethanol, benzene, etc.) are known for their acute and chronic health effects varying from eye or throat irritation to the suspected, or confirmed, case of cancers in worse situations.[1] Detection and quantification of such harmful volatile 
chemical species inside or outside require sensitive materials and versatile devices running on in a large range of conditions (temperature and humidity).[2] Appeared in sixties, gas chromatography generally coupled with a mass spectroscopy or flame ionization detector is a powerful method providing precise measurements even in case of gas mixture. But it needs fairly complicated, cumbersome, time consuming and costly equipment to be routinely used outside of the lab. More recently solid-state gas sensors emerged as a serious alternative due to their low cost, small size and in situ real time response. Generally their sensing mechanism relies on the modification of a physical property (temperature, electrical, magnetic, optical, etc.) of a metal oxide or organic (polymer, graphene, carbon nanotube, etc.) material induced by the interaction with the targeted molecule at its surface.[3-6] Resistive electrical-type gas sensors have been the most studied in the past years, probably due to their relative ease to be integrated in electronic devices, but they suffer some drawbacks as cross-sensitivity, electromagnetic noise dependence or response drift.[7] Optical gas sensors represent innovative alternatives based on the measurement of the change of absorbance, refractive index, or fluorescence property of sensitive materials with the advantages compared to the electrical gas sensors that they are more resistant, operate at room temperature and can be implemented in optical fiber configuration.[8] Moreover optical detection seems promising regarding its simplicity of use and the democratization of smartphones able to record and process optical data, allowing each person to perform their own biological or environmental analyses. $[9,10]$

Solid state optical gas sensors based on sol gel methods already emerged several years ago. Large literature describes sol gel matrix as host for active optical molecules, ions or nanoparticles where the fluorescence quenching, variation of absorbance or variation of surface plasmon resonance of the sensitive guest allow to detect targeted gas with concentration as low as few ppm.[11-14] Porous silica matrixes with high surface specific area, low temperature process, light transparency (> $250 \mathrm{~nm}$ ), high chemical and environmental resistances, and a large range of well-controlled hybrid composition to immobilize a numerous dispersed sensitive phases are ideal candidates for high sensitivity sensors. On the other hand, few works also report that microporous silica could be used as a direct active sensing probe using its ability to capillary adsorbed Volatile Organic Compound (VOC) analyte into the porosity which induces a modification of the refractive index of the materials that can be monitored by optical fiber devices.[15, 16] Despite the exploration of extensive sensing strategies, efforts are still needed to improve selectivity the sol-gel based gas sensor. In particular the adsorption and condensation of water vapor onto the sensitive surfaces is known as one of the main purposes of cross-sensitivity, which drastically limits sensor efficiency in real conditions of humidity and temperature.

In this present work we demonstrate that humidity is not only a parameter affecting the performance of sensors, but it could also be advantageously used in the VOC's detection with the example of a thin film optical ethanol sensor based on the synergic co-adsorption of ethanol and water in mesoporous hydrophobic silica matrix shaped as a diffraction grating by Nanolmprint Lithography (NIL).[17] In the first part, we show that water vapor can be adsorbed and capillary condensed within hydrophobic nanopores at atmospheric pressure conditions and without any external stimulus, using alcohol co-adsorption from the vapor phase. The investigated systems consisted in flat mesoporous methyl-functionalized silica films, composed of interconnected pores with mean diameters adjusted at $2.3 \mathrm{~nm}$ through the 
Evaporation Induced micellar template Self Assembly (EISA) method, standing in atmospheres where relative vapor pressure in water and alcohol were accurately adjusted between 0 and saturation. We demonstrate that the adsorption of alcohol from the atmosphere, even if present at low vapor pressures, is sufficient to increase the surface energy of the pore interface to allow water capillary condensation. In a second part, mesoporous methylfunctionalized silica films were patterned by a recently reported soft-lithographic approach to fabricate nanoimprinted 2D diffraction gratings onto silicon substrate.[18] We showed that the change of refractive index induced by co-adsorption of water-ethanol vapor mixture can be measured using a commercial camera as a variation of the intensity of diffracted light by the silica grating. A linear dependence is observed between the intensity of diffracted light and the partial vapor pressure of the ethanol regardless of the relative humidity, and an enhanced ethanol sensitivity of the sensor was observed in atmosphere saturated by water. These results reveal that humidity is not necessary a crippling for the metal oxide gas sensor and such optical silica-based sensors can likely be extended to other polar VOCs. Structural characteristics of the water repellent mesoporous films were deduced from Field Emission Gun Scanning Electron Microscopy (SEM-FEG) and Environmental Ellipsometric Porosimetry (EEP) investigations. Ethanol and water vapors adsorption and capillary condensation were followed by in situ Environmental Ellipsometry for plain thin film configuration and by image recording for grating configuration.

\section{Experimental section}

Reagents:

Tetraethyl orthosilicate (TEOS), triethoxymethylsilane (MTEOS), hydrochloric acid $(\mathrm{HCl})$ and decyltrimethylammonium (DTAB) were purchased from Aldrich. Absolute ethanol $100 \%$ (EtOH) was purchased from Normapur. All products were used as received.

Thin film processing:

Mesoporous methyl-functionalized silica thin films were synthesized with DTAB template and labeled $\mathrm{M}_{\text {DTAB }}$. Films were prepared from a solution composed of TEOS/MTEOS/DTAB/HCl/ $\mathrm{H}_{2} \mathrm{O} / \mathrm{EtOH}$ with respective molar ratios of 0.5:0.5:0.14:0.15:5:23. First, TEOS and MTEOS were dissolved in mixture of $\mathrm{EtOH}, \mathrm{HCl}(2 \mathrm{M})$ and $\mathrm{H}_{2} \mathrm{O}$ then the template was added. Solutions were stirred at least for $24 \mathrm{~h}$ at room temperature before use. Thin films were prepared on silicon wafer by dip coating at room temperature, and relative humidity of $30 \pm 5 \%$ with a withdrawal rate of $3 \mathrm{~mm} \cdot \mathrm{s}^{-1}$. After deposition, hybrid films were immediately calcinated at $450^{\circ} \mathrm{C}$ for $10 \mathrm{~min}$. In some, later indicated, cases a post methylation was performed by aging the film for $72 \mathrm{~h}$ in $20 \%$ vol of hexamethyldisilazane dissolved in anhydrous toluene, before drying and stabilization at $450^{\circ} \mathrm{C}$ for $10 \mathrm{~min}$. $\mathrm{M}_{\mathrm{DTAB}}$ films that underwent such a treatment were labeled $\mathrm{M}_{\mathrm{DTAB}}{ }^{*}$.

Diffraction grating fabrication:

Mesoporous methyl-functionalized silica diffraction gratings were prepared from the same solution used to prepare $M_{D T A B}$ mesoporous films. A thin film was deposited on silicon wafer by dip coating at room temperature, and relative humidity of $30 \pm 5 \%$ with a withdrawal speed of $10 \mathrm{~mm} \cdot \mathrm{s}^{-1}$. After coating and before drying at room temperature of the siliceous matrix, a 
polydimethylsiloxane (PDMS) based stamp, was immediately molded on the film, applying a slight pressure $\left(\sim 0.1 \mathrm{Kg} \mathrm{cm}^{-2}\right)$ to emboss the micrometric grating. Then the stack of PDMS stamp and substrate was cured at $130^{\circ} \mathrm{C}$ for $10 \mathrm{~min}$, the stamp was removed and the hybrid imprinted grating was calcinated at $450^{\circ} \mathrm{C}$ for $10 \mathrm{~min}$. A post methylation of the microstructures was performed in $20 \% \mathrm{vol}$ of hexamethyldisilazane dissolved in anhydrous toluene, before drying and stabilization at $450^{\circ} \mathrm{C}$ for $10 \mathrm{~min}$.

PDMS stamp fabrication:

A silicon master mold was fabricated by electron beam lithography at $100 \mathrm{KeV}$ (Vistec 5000+) and reactive ion etching. An A7 PMMA positive-tone resist (495PMMA A Resists, solids: 7\% in Anisole) was spin-coated on a 2-inch $\mathrm{Si}(100)$ wafer and baked for $45 \mathrm{~min}$ at $160{ }^{\circ} \mathrm{C}$. The sample was exposed at $10 \mathrm{nA}$ with a dose of $1300 \mu \mathrm{C} / \mathrm{cm} 2$, developed for $45 \mathrm{sec}$ in a solution of methyl-isobutyl-ketone and isopropanol (mixture 1:3), rinsed in isopropanol and gently dried with pure nitrogen gas. The pattern was transferred by reactive ion etching using a SF6/CHF3 gas mixture. An anti-sticking treatment was performed using $1 \mathrm{H}, 1 \mathrm{H}, 2 \mathrm{H}, 2 \mathrm{H}$ Perfluorooctyltriethoxysilane (POTS) by chemical vapor deposition method. A sealed glass Petri dish containing the silicon master and several drops of POTS was heated in an oven at about $120^{\circ} \mathrm{C}$ for $1 \mathrm{~h}$ to enable the reaction between the $\mathrm{OH}$ groups on the Si substrate surfaces and the POTS and then maintained at about $150{ }^{\circ} \mathrm{C}$ for $2 \mathrm{~h}$ to remove the unreacted POTS molecules. Then a bi-layer hard-PDMS/PDMS stamp was then replicated first by spin-coating a thin hard-PDMS layer on the silicon master and secondly by casting a mixture of commercial available (RTV615 from GE) two components solution (1:10) on top. The bi-layer hardPDMS/PDMS stamp was degassed and soft-baked at $60{ }^{\circ} \mathrm{C}$ for $48 \mathrm{~h}$. Finally, after being peeled off from the silicon master, the bi-layer stamp was treated with trichloromethylsilane.[19]

Characterization:

Environmental Ellipsometric analyses were performed on a UV-visible variable angle spectroscopic ellipsometer (M2000 Woolam) equipped with a controlled atmosphere cell. Relative vapor pressures of $\mathrm{H}_{2} \mathrm{O}$ and alcohol inside the chamber were controlled at room temperature $\left(20 \pm 2^{\circ} \mathrm{C}\right)$ by bubbling a dry and filtrated air (flux: $\left.2 \mathrm{~L} . \mathrm{min}^{-1}\right)$ in a home-built assembly of mass flow controllers and bubblers containing either solution of alcohol and water with the respective mass ratio in alcohol of $X$ (weight $\%$ ) $=0 \%, 5 \%, 10 \%, 20 \%, 50 \%, 80 \%, 100 \%$ or pure water as described elsewhere.[20] After each measurement, films were washed with acetone and dried at $350^{\circ} \mathrm{C}$ for $30 \mathrm{sec}$. Each point was taken after $20 \mathrm{~s}$, which was verified to be sufficient to reach equilibration. Films thickness and refractive index were extracted from conventional $\psi$ and $\Delta$ dispersions using a Cauchy model (Wase 32 software). Electron microscopy images showing the film structure and gratings microstructure were collected using a field-emission gun scanning electron microscopy (FEG-SEM - Hitachi SU7000 instrument). The diffracted light beams were observed by Manta allied vision technologies CCD camera placed at an angle $\theta$ of the incident white light source and their relative luminance were analyzed by ImageJ software.

\section{Results and discussion}


I-Ethanol detection by co-condensation with water into hydrophobic pores: mechanism.

$M_{D T A B}$ water repellent methyl-functionalized thin films with average thickness of $200 \mathrm{~nm}$ were synthesized by the evaporation induced self-assembly (EISA) method using DTAB as micellar template and TEOS and MTEOS as precursors. The dip coated thin films composed of pure and hybrid silica precursors in equimolar ratio were thermally cured to condense the siliceous matrix, release the porosity by burning the organic template and confer the hydrophobicity to the porosity.[21, 22] In Figure 1.a, adsorption-desorption isotherms recorded from environmental ellipsometry porosimetry using water as adsorbate for the hybrid $\mathrm{M}_{\text {DTAB }}$ and similar pure silica DTAB templated films are reported. Whereas a water uptake of $32 \%$ is observed for the latter, $\mathrm{M}_{\text {DTAB }}$ exhibits a water adsorption inferior to 3\% confirming the methylgenerated hydrophobicity of pores. Figure 1.b. shows a SEM image of the $\mathrm{M}_{\text {DTAB }}$ film, revealing a disordered worm-like organization of the hybrid mesoporosity. In Figure 1.c and 1.d, the adsorption-desorption isotherm and the pore size distribution respectively are reported for $M_{D T A B}$ films. Due to the hydrophobicity of pores, organic solvent was required as absorbate to perform ellipsometry porosimetry measurements. $[23,24]$ Ethanol isotherm corresponds to a mesoporous structure with interconnected porous networks. A narrow pore size distribution (Figure 1.d) in the range of 1.5-3 $\mathrm{nm}$ was determined using the Kelvin equation[25] from adsorption curve with a corresponding mean pore diameter of $2.30 \pm 0.15 \mathrm{~nm}$.
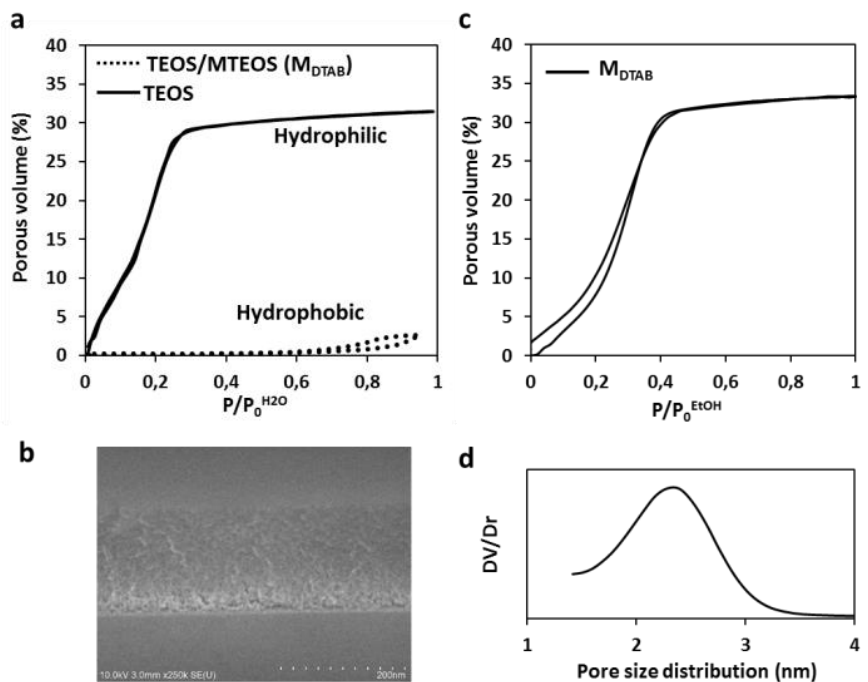

Figure 1. (a) Environmental ellipsometric porosimetry (EEP) using water vapor of pure TEOS film and $50 \mathrm{~mol} \%$ MTEOS/50 mol \% TEOS film (M (МтAB) both with mesopores obtained from DTAB surfactant. (b) SEM-FEG side view image of $M_{\text {DTAB }}$ film. (c) and (d) Ethanol adsorptiondesorption isotherm and corresponding pore size distribution obtained by ellipsometry porosimetry.

Capillary condensation is a phenomenon observed for mesopores having dimension comprised between 2 and $50 \mathrm{~nm}$ and occurs at pressure below the saturation due to capillary forces. The sudden filling with a liquid phase of pores is responsible for an abrupt increase of the global refractive index of the thin film that can be monitored by in situ ellipsometry. In dry 
atmosphere direct capillary condensation of ethanol into hydrophobic pores of $M_{D T A B}$ is observed at the relatively high vapor pressure of $\mathrm{P} / \mathrm{P}_{0}{ }^{\mathrm{EtOH}}=0.32$ (Figure 1.c). The capillary filling of these mesopores in atmosphere composed this time of water and ethanol has been investigated in following part. In Figure 2, the liquid phase content in $\mathrm{M}_{\mathrm{DTAB}}$ films, extracted from the variation of the refractive index of the hybrid thin films, is plotted using Bruggeman effective medium approximation.[26] Four successive steps are reported during which the atmosphere composition in ethanol and water have been adjusted in the measurement chamber. In a first step, dry air ensures the complete desorption of the porosity. In a second step, the sharp increase in humidity from $\mathrm{P} / \mathrm{P}_{0}{ }^{\mathrm{H} 2 \mathrm{O}}=0$ to $\mathrm{P} / \mathrm{P}_{0}{ }^{\mathrm{H} 2 \mathrm{O}}=1$ is marked by water uptake of $8 \%$ for $\mathrm{M}_{\mathrm{DTAB}}$, confirming the hydrophobicity of the hybrid film but also suggesting that at nanoscale the surface of pores is only partially covered with methyl groups. It is highly probable that polar silanol groups $(\mathrm{Si}-\mathrm{OH})$ are remaining into the mesopores, enabling the adsorption of a small amount of water. Similar successive multi-steps experiment was also reported for hybrid post methylated $\mathrm{M}_{\mathrm{DTAB}}{ }^{*}$ in Figure 2. Lower water uptake value of $3 \%$ for $M_{D T A B}{ }^{*}$ is observed in atmosphere saturated by water, indicating that post methylation step significantly decreases the remaining surface number of hydroxyl of the hybrid film synthesized by co-condensation, turning a part of hydrophilic - $\mathrm{OH}$ groups into hydrophobic $\mathrm{O}-\mathrm{Si}\left(\mathrm{CH}_{3}\right)_{3}$ groups. The atmosphere is modified in step three by adding ethanol. Vapor mixture composed of $\mathrm{P} / \mathrm{P}_{0}{ }^{\mathrm{EOH}}=0.07 ; \mathrm{P} / \mathrm{P}_{0}{ }^{\mathrm{H} 2 \mathrm{O}}=0.97$ provoked an abrupt increase of the refractive index corresponding to the capillary condensation of vapors and filling up the full porous volume with a liquid phase, both for $M_{D T A B}$ and $M_{D T A B} *$ films. The capillary filling of $M_{D T A B}$ is 6 time faster than $\mathrm{M}_{\mathrm{DTAB}}{ }^{*}$, highlighting that a higher density of $-\mathrm{OH}$ in surface have a probable effect on the kinetic of the pore filling by a liquid phase that we supposed mainly composed of water. Indeed, there is no reason that capillary condensed liquid is not in thermodynamic equilibrium with the atmosphere almost saturated in water. This sudden adsorption and capillary condensation of water in hydrophobic pores underlines the influence of a little amount of ethanol in quasi-saturated humid atmospheres and reveal its critical role to modify the surface energy of pores. Indeed ethanol, as a co-adsorbate with water, plays the role of surfactant at the pore/liquid interface. Ethanol organic moiety interacts with the surface methyl groups, resulting in a particular ethanol conformation where the alcoholic polar head $(-\mathrm{OH})$ is turned toward the center of pores in interaction with water molecules, accommodating the surface energy gap between water and hydrophobic pore. Very interestingly, in the last step when atmosphere is similar to step two $\left(\mathrm{P} / \mathrm{P}_{0}{ }^{\mathrm{EtOH}}=0 ; \mathrm{P} / \mathrm{P}_{0}{ }^{\mathrm{H} 2 \mathrm{O}}=1\right)$ porosities of $\mathrm{M}_{\text {DTAB }}$ and $\mathrm{M}_{\text {DTAB }}$ * films stay partially filled at $93 \%$ and $23 \%$ respectively, which is much higher than what is observed in step 2 ( $8 \%$ and $3 \%$ for $M_{D T A B}$ and $M_{D T A B}$ * respectively). In both cases, by modifying the equilibrium state between steps 3 and 4 , a highly probable selective desorption of ethanol occurs into the porosity, leading to the destabilization of the liquid/pore interfaces and the partial spontaneous water desorption in water saturated atmosphere. In other words this presume selective desorption of the co-adsorbate (ethanol) permits to trap water liquid phase into hydrophobic pores at room temperature and atmospheric pressure by a simple ethanolwater co-adsorption and selective desorption of the alcoholic co-adsorbate. We demonstrated that the control of pore surface chemistry (balance between surface density of silanol groups 
and methyl groups) as well as the pore size and the kind of co-adsorbate are the critical parameters that govern the trapping of liquid water into hydrophobic pores by a simple coadsorption and selective desorption sequence. These results have been more deeply discussed in another article.[20]

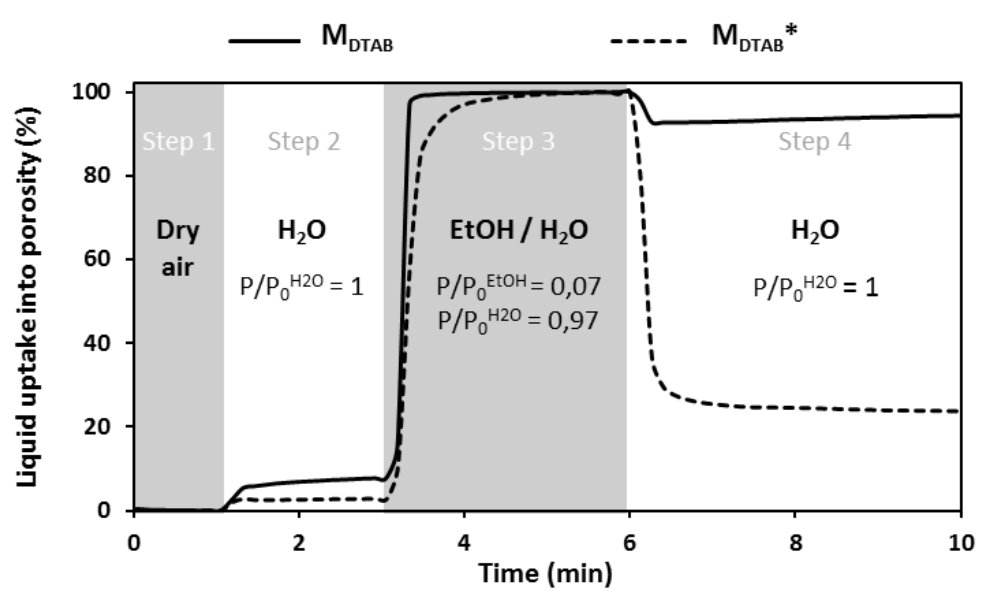

Figure 2. Time resolved porosity filling for $M_{D T A B}$ and $M_{D T A B} *$ films depending on four successive atmospheres with the following compositions in ethanol and water: step $1\left(\mathrm{P} / \mathrm{P}_{0}{ }^{\mathrm{EtOH}}=0\right.$; $\left.\mathrm{P} / \mathrm{P}_{0}{ }^{\mathrm{H} 2 \mathrm{O}}=0\right)$, step $2\left(\mathrm{P} / \mathrm{P}_{0}{ }^{\mathrm{EtOH}}=0 ; \mathrm{P} / \mathrm{P}_{0}{ }^{\mathrm{H} 2 \mathrm{O}}=1\right)$, step $3\left(\mathrm{P} / \mathrm{P}_{0}{ }^{\text {EtOH }}=0.07 ; \mathrm{P} / \mathrm{P}_{0}{ }^{\mathrm{H} 2 \mathrm{O}}=0.97\right)$ and step 4 $\left(\mathrm{P} / \mathrm{P}_{0}{ }^{\mathrm{EtOH}}=0 ; \mathrm{P} / \mathrm{P}_{0}{ }^{\mathrm{H} 2 \mathrm{O}}=1\right)$.

Co-adsorption of ethanol and water into porous $\mathrm{M}_{\mathrm{DTAB}}$ films, for different hydro-ethanolic atmospheres, were further investigated using ellipsometry porosimetry. Several atmospheres were generated by controlled-volume mixing of dry air and air saturated from ethanol/water solutions with various compositions (see experimental part). Vapor pressure ratio of ethanol $\mathrm{P}^{\mathrm{EtOH}} / \mathrm{P}^{\text {Total }}$ where $\mathrm{P}_{\text {Total }}=\mathrm{P}^{\mathrm{EtOH}}+\mathrm{P}^{\mathrm{H} 2 \mathrm{O}}$ of the generated atmosphere remains constant in the measurement chamber, but individual partial vapor pressures of ethanol and water are simultaneously and proportionally modulated by mixing with dry air. Figure 3 reports adsorption-desorption isotherms obtained with $\mathrm{M} D T A B_{\text {films for different vapor pressure ratios }}$ of ethanol. Isotherms are plotted as a function of $\mathrm{P} / \mathrm{P}_{0}{ }^{\mathrm{EtOH}}$ and $\mathrm{P} / \mathrm{P}_{0}{ }^{\mathrm{H} 2 \mathrm{O}}$. Isotherms obtained for $\mathrm{P}^{\mathrm{EtOH}} / \mathrm{P}^{\text {Total }}=0$, corresponding to an atmosphere without ethanol and a water partial vapor pressure comprised between $\mathrm{P} / \mathrm{P}_{0}{ }^{\mathrm{H} 2 \mathrm{O}}=0$ and $\mathrm{P} / \mathrm{P}_{0}{ }^{\mathrm{H} 2 \mathrm{O}}=1$, show a low water uptake as expected due to the hydrophobicity of pores. At the opposite when $\mathrm{P}^{\mathrm{EtOH}} / \mathrm{P}^{\text {Total }}=1$ and atmosphere is only composed of ethanol with $0<\mathrm{P} / \mathrm{P}_{0}{ }^{\mathrm{EtOH}}<1$, we obtained the capillary condensation and filling of the entire porous volume by liquid ethanol at $\mathrm{P} / \mathrm{P}_{0}{ }^{\mathrm{EtOH}}=0.32$ as already observed in Figure 1. Isotherms obtained for intermediate $\mathrm{P}^{\mathrm{EtOH}} / \mathrm{P}^{\text {Total }}$ reveal that $\mathrm{P} / \mathrm{P}_{0}{ }^{\mathrm{EtOH}}$ and $\mathrm{P} / \mathrm{P}_{0}{ }^{\mathrm{H} 2 \mathrm{O}}$ values at the capillary condensation increase and decrease respectively when $\mathrm{P}^{\mathrm{EtOH}} / \mathrm{P}^{\text {Total }}$ increases from 0.16 to 0.74 . The change of the partial vapor pressure conditions for the capillary condensation with $\mathrm{P}^{\mathrm{EtOH}} / \mathrm{P}^{\text {Total }}$ indicates a synergic mechanism of adsorption/desorption between ethanol and water and support explanations deduced from previous experiments. In these experiments the mass flow controllers/bubblers set-up did not allow independent variations of ethanol and water pressures which made difficult the dissociation of $\mathrm{P} / \mathrm{P}_{0}{ }^{\mathrm{EtOH}}$ and 
$\mathrm{P} / \mathrm{P}_{0}{ }^{\mathrm{H} 2 \mathrm{O}}$ to discuss the isotherms. Nevertheless for each $\mathrm{P}^{\mathrm{EtOH}} / \mathrm{P}^{\mathrm{Total}}$, a couple of partial vapor pressure in ethanol and water can be distinctly determined (reported in Figure 3 ) and correspond to the maximal partial vapor pressure of water and the minimal partial vapor pressure of ethanol to obtain the capillary fillings of the pores. In other words, for a fixed ethanol partial vapor pressure value, capillary adsorption occurs only if water partial vapor pressure is over this critical value. As an example for $\mathrm{P} / \mathrm{P}_{0}{ }^{\mathrm{EtOH}}=0.07, \mathrm{P} / \mathrm{P}_{0}{ }^{\mathrm{H} 2 \mathrm{O}}$ has to be superior to 0.95 otherwise only adsorption or partial capillary filling are observed. The lower ethanol partial pressure required for capillary filling of pores in humid atmospheres, compared to the one observe in dry atmosphere, indicates that whether ethanol adsorption onto hydrophobic pore surface is essential to turn the hydrophobic surface to hydrophilic. This is water that governs the capillary condensation. In next part, this ethanol-assisted water condensation mechanism into hydrophobic pores is demonstrated, using 2D photonic systems, as innovative way to optically detect ethanol vapor in both dry and humid atmosphere.

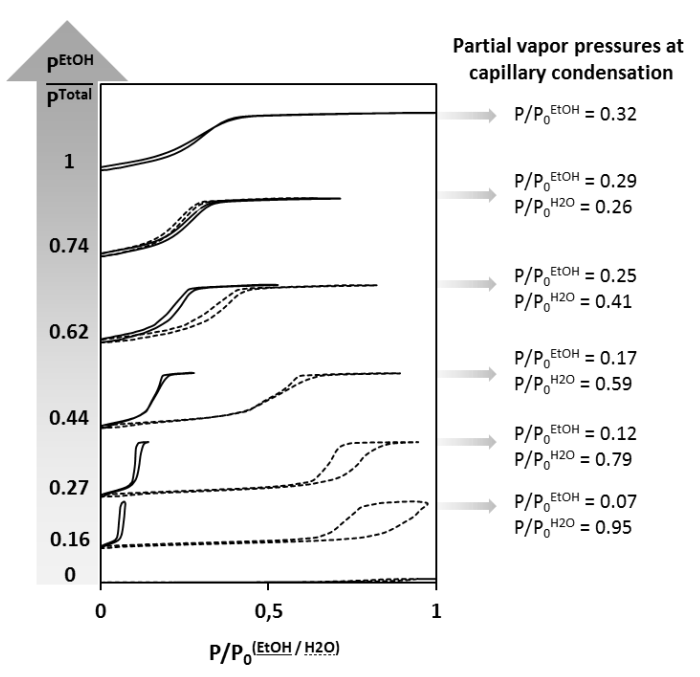

Figure 3. Adsorption-desorption isotherms for $M_{D T A B}$ film versus partial vapor pressures of ethanol (black line) and water (black dotted) for various fraction of vapor pressures $\left(\mathrm{P}^{\mathrm{EtOH}} /\left(\mathrm{P}^{\mathrm{EtOH}}+\mathrm{P}^{\mathrm{H} 2 \mathrm{O}}\right)\right)$ indicated on the left side.

II- Photonic ethanol sensor in humid environment.

Nanometer scale diffraction gratings for the optical detection and quantification of ethanol vapors in real humid atmospheric conditions were fabricated by combination of sol gel and nanoimprint lithography methods. The process for the synthesis of diffracting gratings is reported in Figure 4. 


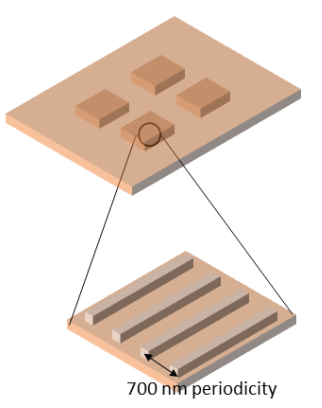

I. PDMS micro stamp

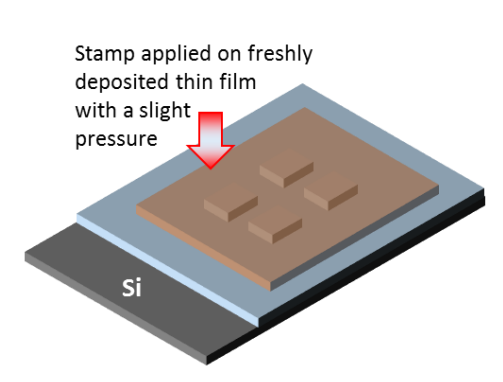

II. Sol gel film embossing

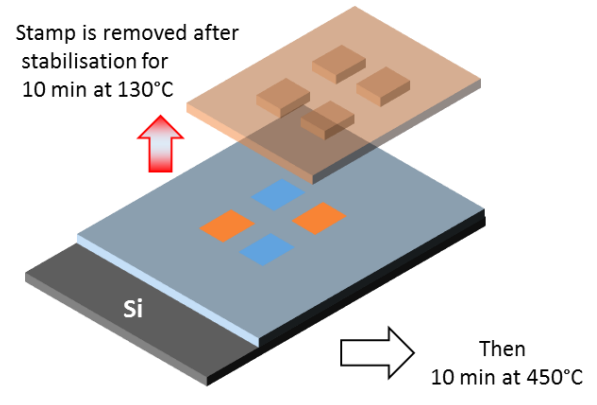

III. Nanometric diffraction gratings

Figure 4. Illustration of the process of fabrication of the silica based hydrophobic mesoporous gratings for light diffraction.

Briefly, solution used to prepare $M_{\text {DTAB }}$ mesoporous thin films was deposited on silicon wafer by dip coating. Immediately after coating deposition, a PDMS-based stamp was molded on the siliceous matrix film by applying a slight pressure. Then the stack of PDMS stamp and substrate was cured at $130^{\circ} \mathrm{C}$ for $10 \mathrm{~min}$, the stamp was removed, and the imprinted nanopatterns were calcinated at $450^{\circ} \mathrm{C}$ for $10 \mathrm{~min}$. The resulting hybrid silica nanostructures were post methylated in the same way as $\mathrm{M}_{\mathrm{DTAB}}$ * thin films to obtain a similar surface chemistry, showing low water uptake and good ethanol sensitivity as observed in Figure 2. Due to the use of same sol gel solution and very similar processes, the mesoporous structure of nanopatterns is similar as $M_{D T A B}$ thin film, with interconnected porous networks and mean pore diameter of $2.12 \pm 0.15$ $\mathrm{nm}$.

The pattern is composed of a square array of silica-based two dimensional rectangular nanogrooves. Figure 5.a shows a scanning electron microscope image of an array of nano-groove with a periodicity of $700 \mathrm{~nm}$. Each 2D nanostructure individually scatters the incident light in all direction. Due to the regular disposition of the nanostructures, scattered electromagnetic waves interfered resulting in alternatively destructive and constructive interferences. Resulting diffracted light was monitored by a camera, working wavelengths were selected depending on the angle of observation with respect to the incident beam, as illustrated in Figure 5.b. Indeed, considering a white light beam at an incident angle of $90^{\circ}$ the diffraction angles as function of the wavelength is given by the Bragg's equation as $\theta=\sin ^{-1}(m \lambda / d)$, where $\lambda, m$, and $d$ are the wavelength of the diffracted beam, an integer representing the order of diffraction and the periodicity of the array respectively.

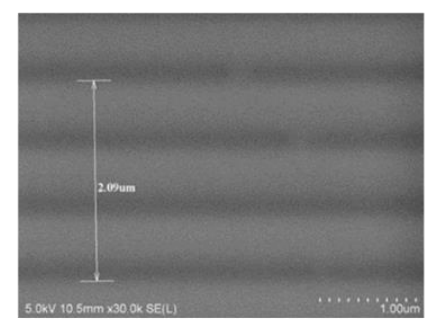

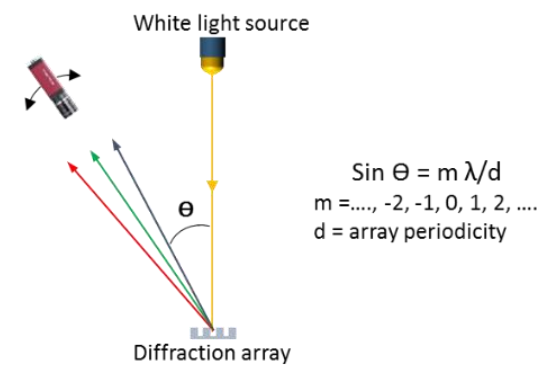

Figure 5. (a) SEM-FEG top view image of nanopatterned array. (b) Illustration of the diffracted light observed in reflection with a camera for a white light source placed with an incident angle of $90^{\circ}$. 
Diffracted light beams at average selected angles of $\theta=37^{\circ}$ or $\theta=54^{\circ}$ were observed by a CCD camera allowing to record the relative luminous flux. Then relative luminance variations were extracted from pattern pictures using ImageJ software for a small selected area of the pattern, see Figure 6 . The relative luminance of diffracted light was calculated in the RGB color space from the formula, $L=0.2126 R+0.7152 G+0.0722 B$, where $R, G$, and $B$ are the red, green, and blue contributions of the light composition multiply by coefficients corresponding to the intensity perceived by the trichromatic human vision. Intensity of the relative luminance for a monochromatic wave diffracted by a grating depends on power and polarization of the incident light, angles of incidence and diffraction, groove periodicity and difference of refractive index $(\Delta n)$ between the diffractive material and its surrounding environment. All these parameters were kept constant all along the experiments except the refractive index of the porous pattern varying as a function of composition of the atmosphere in water and ethanol. In our case the porous water repellent nanopatterned structure gets a refractive index $\mathrm{n} \approx 1.25$ when pores are empty that increases up to $\mathrm{n} \approx 1.39$ when pores are filled up with liquid by the capillary co-condensation of water and ethanol. In Figure 6 we report a schematic illustration of the refractive index modification and the corresponding pictures of the diffraction gratings showing the increase of the luminance induced by the increase of $\Delta n$.

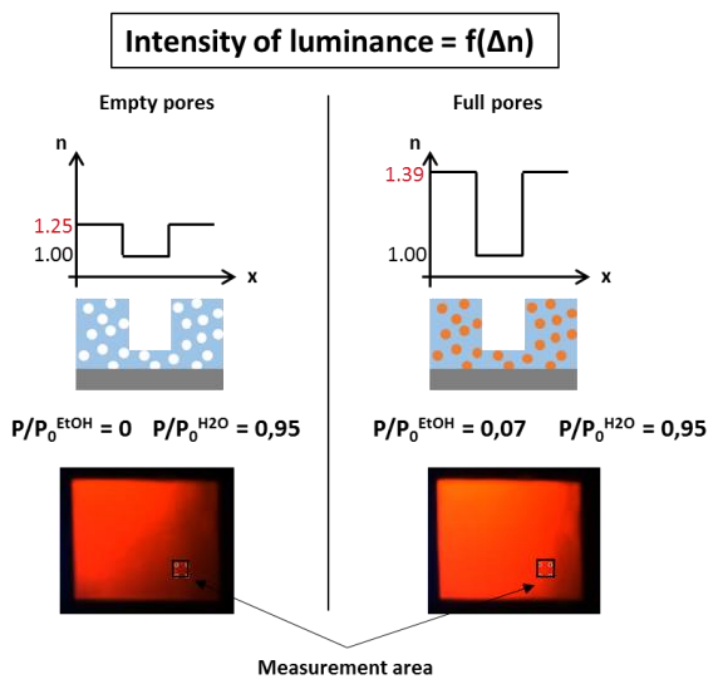

Figure 6. Illustration of the refractive index modification of porous nanopattern induced by the co-adsorption of ethanol and water into hydrophobic pore depending on the $\mathrm{P} / \mathrm{P}_{0}{ }^{\mathrm{EtOH}}$ at a fixed $\mathrm{P} / \mathrm{P}_{0}{ }^{\mathrm{H} 2 \mathrm{O}}$ and the corresponding pictures of diffracted light for observation angle of $\Theta=54^{\circ}$. The black square on pictures indicates the selected area for relative luminance measurement.

Co-adsorption of ethanol and water into porous gratings was investigated by monitoring the relative luminance evolution when hydro-ethanolic atmosphere composition was modified. Atmospheres were generated by controlled-volume mixing of dry air and air saturated from ethanol/water solutions with compositions $\mathrm{X}_{\mathrm{EtOH}}=10 \%, 20 \%, 50 \%$ and $100 \%$. Vapor pressure ethanol to water ratio of these generated atmospheres remained constant in the measurement chamber, but individual partial vapor pressures of ethanol and water are simultaneously and proportionally modulated by mixing with dry air. Figure 7.a reports an 
example of adsorption-desorption isotherm obtained with water repellent grating and a hydroalcoholic atmospheres obtained from the mixture $\mathrm{X}_{\mathrm{EtOH}}=20 \%$, where relative luminance is plotted depending on the global partial vapor pressure in ethanol and water.
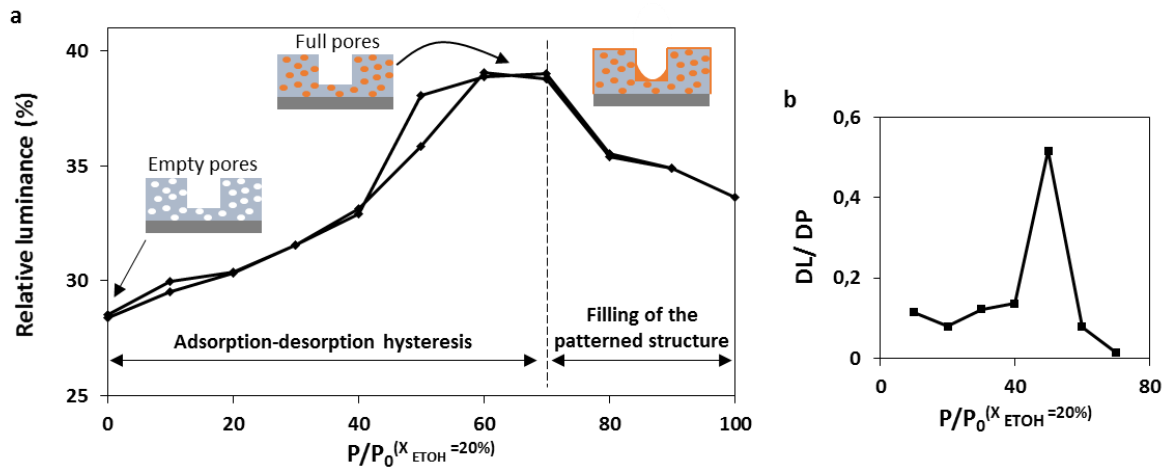

Figure 7. (a) Adsorption-desorption isotherm obtained by diffraction grating relative luminance measurement as a function of partial vapor pressure of ethanol and water generated by an ethanol-water mixture composed of $\mathrm{X}_{\mathrm{EtOH}}=20 \%$. (b) Derivative of the relative luminance from the adsorption branch versus the global partial vapor pressure obtained from mixture $\mathrm{X}_{\mathrm{EtOH}}=$ $20 \%$.

For partial pressures comprised between $P / P_{0}{ }^{X_{E O H}}=20 \%=0 \%$ and $P / P_{0}{ }^{X_{\mathrm{EOHH}}=20 \%}=70 \%$, isotherm is typical of mesoporous structures with interconnected porous networks, confirming that the hybrid mesostructured of gratings is similar as MDTAB thin films. Maximum luminance is obtained for $\mathrm{P} / \mathrm{P}_{0}{ }_{\mathrm{EtOH}}=20 \%=70 \%$ corresponding to the full porous volume filling up with liquid by ethanol-water co-adsorption as mentioned above. One notes a diminution of the relative luminance over capillary filling which cannot be attributed to the decrease of refraction index contrast between the air $\left(n_{\text {air }}=1\right)$ and the capillary filled nanopatterned structure $\left(n_{\text {structure }}=\right.$ 1.39). It is probable that molecules of ethanol, already adsorbed for the low pressure, onto the external surface of the grating favor the nucleation/condensation of water nanodroplets onto the hybrid silica nanopattern for the high partial vapor pressures. Such droplets can form a thin layer of liquid at the surface of the structure and fill a part of nano-grooves as described in the schemes (Figure 7.a, insert). With a refractive index comprised between $\mathrm{n}_{\mathrm{H} 2 \mathrm{O}}=1.33$ and $\mathrm{n}_{\mathrm{EtOH}}=1.36$ close to the one of the diffractive structure, the condensed liquid phase in nanostructure changes the two dimensional "optical density profile" of the groove array, affecting the diffraction capability of the grating. Such decrease of luminance intensity likely related to the apparent nanostructure geometry modification of the $2 \mathrm{D}$ arrays that damages the photonic properties of the diffraction gratings was observed only for partial vapor pressures after capillary co-condensation, and so does not interfere with ethanol-water coadsorption.

For each ethanol mixture $\mathrm{X}_{\mathrm{EtOH}}=10 \%, 20 \%, 50 \%$ and $100 \%$, derivatives of the relative luminance were plotted versus $\mathrm{P} / \mathrm{P}_{0}{ }^{\left(\mathrm{E}_{\mathrm{EtOH}}\right)}$, (data for $\mathrm{X}_{\mathrm{EtOH}}=20 \%$ is presented in Figure 7.b). Their respective local maxima, corresponding to the capillary condensation into the porosity, were reported in Figure 8.a and presented depending on the relative humidity and the partial vapor pressure in ethanol of the atmosphere. 


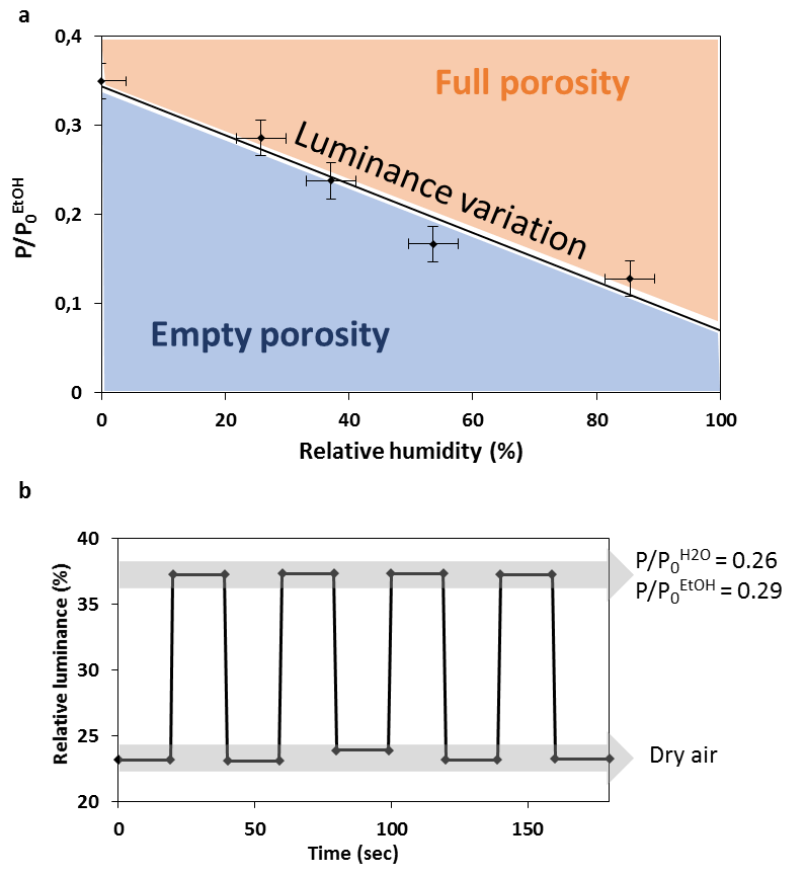

Figure 8. (a) Abrupt relative luminance variation recorded at capillary condensation (extracted from derivatives of luminance of adsorption desorption isotherms) reported as a function of relative humidity and ethanol partial vapor pressure of the atmosphere triggering the pore filling. (b) Relative luminance of a diffraction grating during four cycles of successive atmosphere of dry air and $\mathrm{P} / \mathrm{P}_{0}{ }^{\mathrm{H} 2 \mathrm{O}}=0.26, \mathrm{P} / \mathrm{P}_{0}{ }^{\mathrm{EtOH}}=0.29$.

The plotted curve in Figure 8.a represents the calibration curve of the optical ethanol sensor, and demonstrates that ethanol vapor concentration can be easily determined by monitoring the capillary co-condensation induced luminance variation with water into hydrophobic mesoporous silica based diffraction gratings in known humid atmosphere. The nanopatterned array fabricated with a DTAB templated silica matrix exhibits a linear response and detection of ethanol vapors in the range from $\mathrm{P} / \mathrm{P}_{0}{ }^{\mathrm{EtOH}}=0.13 \pm 0.02$ to $\mathrm{P} / \mathrm{P}_{0}{ }^{\mathrm{EtOH}}=0.35 \pm 0.02$ within a good experimental error in both humid and dry atmosphere. A threshold limit of detection of $\mathrm{P} / \mathrm{P}_{0}{ }^{\mathrm{EtOH}}=0.07$ at $100 \%$ of humidity was estimated. In a previous paper we demonstrated that minimum ethanol vapor pressure required for the water condensation into hydrophobic pores depends on the pore size.[20] Therefore, it can be imagine to extend the range of detection either for higher or lower ethanol amounts by associating several diffraction gratings with different pore sizes. Such optical sensor devices would require further investigations about fairly complicated optical acquisition system able to record and process in parallel and simultaneously larger quantity of data, but are out of the scope of this article. Eventually, in Figure 8.b, maximum and minimum luminance values recorded for four adsorption and desorption cycles are represented with successive dry air and $\mathrm{P} / \mathrm{P}_{0}{ }^{\mathrm{H} 2 \mathrm{O}}=0.26, \mathrm{P} / \mathrm{P}_{0}{ }^{\mathrm{EtOH}}=0.29$ atmospheres. One remarks that same relative luminance values of $23 \%$ when pores are empty and $37 \%$ when pore are full are observed for each isotherms, indicating that the response of the sensors is not affected after several runs. The measurement sensitivity is highly reproducible, meaning that repetition of measurement cycle do not induce any porosity structure and surface chemistry modifications. In addition fast measurements in the order of 
the second were observed with maximum detection and recovering time of $30 \mathrm{sec}$ for the lower ethanol concentration.

\section{Conclusion}

A nanoimprinted photonic vapor sensor based on hydrophobic mesoporous $\mathrm{SiO}_{2}$ diffraction gratings was fabricated and tested against the detection of trace of ethanol in simulated ambient atmosphere. First, ellipsometry investigations of the capillary filling of the methyl functionalized pores in humid atmosphere containing small amount of ethanol showed that water could condensed only due to the preferential ethanol adsorption onto the water repellent surfaces, playing the role of surfactant and turning the hydrophobic surface energy into hydrophilic. We also demonstrated that conditions at which capillary co-condensation occurs were strongly dependent of humidity and amount of ethanol. Then, the abrupt modification of the refractive index of inorganic matrix accompanying the filling up of the porosity was exploited to induce variation of luminance of diffraction gratings and signaled the presence of ethanol in atmosphere. A sensitivity from $\mathrm{P} / \mathrm{P}_{0}{ }^{\mathrm{EtOH}}=0.35$ to $\mathrm{P} / \mathrm{P}_{0}{ }^{\mathrm{EtOH}}=0.13$ was obtained for $2.30 \mathrm{~nm}$ pore size depending on the relative humidity varying from $0 \%$ to $85 \%$, and a threshold limit of detection of $\mathrm{P} / \mathrm{P}_{0}{ }^{\mathrm{EtOH}}=0.07$ at $100 \%$ of humidity was estimated. The fast response, good sensitivity, simplicity and robustness of this new type of sensor validate the concept of ethanol detection by the mechanism of co-adsorption with water in hydrophobic mesopores. It also demonstrates that an all-integrated sensor that would decorelate the competing adsorption of water and alcohol respectively could be simply envisioned by integrating an optical relative humidity measurement, to evaluate the relative pressure of ethanol in ambient atmosphere.

\section{Author information}

Corresponding Authors

E-mail: marco.faustini@upmc.fr

E-mail: boudot@cm.kyushu-u.ac.jp

\section{Acknowledgment}

We are grateful for funding provided by CIFRE fund granted by ANRT and the AVATAR project which is supported by Polyrise SAS, and DGA. M. Boudot et al. thanks D. Montero for SEMFEG microscopy conducted on a Hitachi Su-70 + Oxford XMax facilited by the IMPC (FR2482) financially supported by the C'Nano projects of the Region lle-de-France.

\section{References}

1. Kampa M, Castanas E (2008) Human health effects of air pollution. Environ Pollut 151:362-7. doi: 10.1016/j.envpol.2007.06.012 
2. Bruce N, Perez-Padilla R, Albalak R (2000) Indoor air pollution in developing countries: a major environmental and public health challenge. Bull World Health Organ 78:10781092. doi: 10.1590/S0042-96862000000900004

3. Della Gaspera E, Guglielmi M, Martucci A (2015) Sol-Gel for Gas Sensing Applications. In: Sol-Gel Handb. Wiley-VCH Verlag GmbH \& Co. KGaA, Weinheim, Germany, pp 11731206

4. Yoon HJ, Jun DH, Yang JH, et al. (2011) Carbon dioxide gas sensor using a graphene sheet. Sensors Actuators B Chem 157:310-313. doi: 10.1016/j.snb.2011.03.035

5. Kong J (2000) Nanotube Molecular Wires as Chemical Sensors. Science (80- ) 287:622625. doi: 10.1126/science.287.5453.622

6. Eranna G, Joshi BC, Runthala DP, Gupta RP (2004) Oxide Materials for Development of Integrated Gas Sensors-A Comprehensive Review. Crit Rev Solid State Mater Sci 29:111-188. doi: 10.1080/10408430490888977

7. Brigo L, Cittadini M, Artiglia L, et al. (2013) Xylene sensing properties of aryl-bridged polysilsesquioxane thin films coupled to gold nanoparticles. J Mater Chem C 1:4252. doi: 10.1039/c3tc30426d

8. Wang X-D, Wolfbeis OS (2013) Fiber-Optic Chemical Sensors and Biosensors (20082012). Anal Chem 85:487-508. doi: 10.1021/ac303159b

9. Gallegos D, Long KD, Yu H, et al. (2013) Label-free biodetection using a smartphone. Lab Chip 13:2124. doi: 10.1039/c3lc40991k

10. Snik F, Rietjens JHH, Apituley A, et al. (2014) Mapping atmospheric aerosols with a citizen science network of smartphone spectropolarimeters. Geophys Res Lett 41:73517358. doi: 10.1002/2014GL061462

11. JERONIMO P, ARAUJO A, CONCEICAOBSMMONTENEGRO M (2007) Optical sensors and biosensors based on sol-gel films. Talanta 72:13-27. doi: 10.1016/j.talanta.2006.09.029

12. McDonagh C, MacCraith BD, McEvoy AK (1998) Tailoring of Sol-Gel Films for Optical Sensing of Oxygen in Gas and Aqueous Phase. Anal Chem 70:45-50. doi: 10.1021/ac970461b

13. Chu C-S, Lo Y-L (2009) Highly sensitive and linear optical fiber carbon dioxide sensor based on sol-gel matrix doped with silica particles and HPTS. Sensors Actuators B Chem 
143:205-210. doi: 10.1016/j.snb.2009.09.019

14. Hasani M, Coto García AM, Costa-Fernández JM, Sanz-Medel A (2010) Sol-gels doped with polymer-coated $\mathrm{ZnS} / \mathrm{CdSe}$ quantum dots for the detection of organic vapors. Sensors Actuators B Chem 144:198-202. doi: 10.1016/j.snb.2009.10.066

15. Abdelghani A, Chovelon JM, Jaffrezic-Renault N, et al. (1997) Optical fibre sensor coated with porous silica layers for gas and chemical vapour detection. Sensors Actuators B Chem 44:495-498. doi: 10.1016/S0925-4005(97)00172-X

16. Echeverría JC, de Vicente P, Estella J, Garrido JJ (2012) A fiber-optic sensor to detect volatile organic compounds based on a porous silica xerogel film. Talanta 99:433-440. doi: 10.1016/j.talanta.2012.06.007

17. Yu C-C, Chen H-L (2015) Nanoimprint technology for patterning functional materials and its applications. Microelectron Eng 132:98-119. doi: 10.1016/j.mee.2014.10.015

18. Dalstein O, Ceratti DR, Boissière C, et al. (2015) Nanoimprinted, Submicrometric, MOFBased 2D Photonic Structures: Toward Easy Selective Vapors Sensing by a Smartphone Camera. Adv Funct Mater n/a-n/a. doi: 10.1002/adfm.201503016

19. Cattoni A, Cambril E, Decanini D, et al. (2010) Soft UV-NIL at 20nm scale using flexible bi-layer stamp casted on HSQ master mold. Microelectron Eng 87:1015-1018. doi: 10.1016/j.mee.2009.11.106

20. Boudot M, Ceratti DR, Faustini M, et al. (2014) Alcohol-Assisted Water Condensation and Stabilization into Hydrophobic Mesoporosity. J Phys Chem C 118:23907-23917. doi: 10.1021/jp508372d

21. Boudot M, Gaud V, Louarn M, et al. (2014) Sol-Gel Based Hydrophobic Antireflective Coatings on Organic Substrates: A Detailed Investigation of Ammonia Vapor Treatment (AVT). Chem Mater 26:1822-1833. doi: 10.1021/cm403787v

22. Cagnol F, Grosso D, Sanchez C (2004) A general one-pot process leading to highly functionalised ordered mesoporous silica films. Chem Commun (Camb) 1742-3. doi: $10.1039 / \mathrm{b} 403753 \mathrm{~g}$

23. Faustini M, Nicole L, Boissière C, et al. (2010) Hydrophobic, Antireflective, Self-Cleaning, and Antifogging Sol-Gel Coatings: An Example of Multifunctional Nanostructured Materials for Photovoltaic Cells. Chem Mater 22:4406-4413. doi: 10.1021/cm100937e 
24. Vayer M, Nguyen TH, Grosso D, et al. (2011) Characterization of Nanoporous Polystyrene Thin Films by Environmental Ellipsometric Porosimetry. Macromolecules 44:8892-8897. doi: 10.1021/ma201497z

25. Gregg SJ, Sing KSW (1991) Adsorption, surface area, and porosity, Academic P.

26. Niklasson G a, Granqvist CG, Hunderi O (1981) Effective medium models for the optical properties of inhomogeneous materials. Appl Opt 20:26-30. 